\title{
Variability of expression of cyanogenesis in white clover (Trifolium repens L.)
}

Irène Till

The pattern of inheritance of the polymorphism of cyanogenesis in white clover, i.e., of two independent loci with a pair of alleles at each locus, is shown to be too simple. Several phenotypes can coexist at the same time in the same plant, without showing any detectable pattern in space or time. A study of the inheritance of this intra-individual heterogeneity showed that homogeneity is dominant over heterogeneity and that the heterogeneity of a plant increases with the number of its heterogeneous parents. The ecological and evolutionary significance of the phenotypic heterogeneity is discussed.

\section{INTRODUCTION}

A plant is said to be cyanogenic when it releases hydrogen cyanide ( $\mathrm{HCN}$ ) from damaged tissues. Cyanogenesis in the leaves of Trifolium repens $\mathrm{L}$., white clover, results from the hydrolysis of two cyano- $\beta$-glucosides (linamarin: 2-hydroxyisobutyronitrile- $\beta$-D-glucopyranoside; lotaustralin: (R)-(hydroxy-2-methylbutyronitrile- $\beta$-Dglucopyranoside)) by a specific $\beta$-glucosidase (linamarase). The two cyanoglucosides are synthesized from valine and isoleucine respectively (e.g., Cutler and Conn, 1982) by the same biosynthetic pathway (Collinge and Hughes, 1984). In intact leaves the substrates and enzymes are kept separate. It is known that the linamarase is located in the cell walls of epidermal cells in the leaves of $T$. repens (Boersma et al., 1983; Kakes, 1985). It is only surmise from other work that the cyanoglucosides may be stored in the vacuoles of these cells (Kojima et al., 1979; Cutler and Conn, 1982).

From formal breeding work Corkill (1942) proposed that the inheritance of cyanogenesis involves two independent loci each with two alleles. For each locus the dominant allele determines the presence of either the glucosides $(A C)$ or the enzyme $(\mathrm{Li})$. This interpretation has been widely accepted (Daday, 1954a, b, 1958; Chakravarty, 1963; De Arraujo, 1976; Cahn and Harper, 1976; Burdon,

Present address: GPDP-CNRS, 91190 Gif Sur Yvette, France.
1980; Dirzo and Harper, 1982). Thus there are nine possible genotypes and four phenotypes that can be readily identified by appropriate tests (Corkill, 1940 ), giving $F_{2}$ ratios of $9: 3: 3: 1$ for plants having both the glucosides and the enzyme (GE), only the glucosides (G-), only the enzyme (-E) and neither (- ) and of 9:7 for cyanogenic (GE) to acyanogenic (G-, -E and --) plants.

A similar pattern of inheritance has been observed with Lotus cornicultus L. although this plant is a tetraploid showing tetrasomic inheritance at these two loci (Dawson, 1941; Bansal 1971; Ramnani and Jones, 1984).

Quantitative variation in $\mathrm{HCN}$ production has frequently been recorded (Doak, 1933; Williams, 1939; Daday 1954a; Jones, 1966). In T. repens there is a clear allele dosage effect, the homozygous $A c A c$ individuals producing, on average, more than twice the mass of the cyanoglucosides that can be found in heterozygous $A c$ ac plants (Hughes and Stirling, 1982).

All four phenotypes can be found in almost all populations of $T$. repens (e.g., Daday, 1954a, b) and therefore the species is polymorphic at both loci. In attempts to explain this genetic polymorphism, two selective forces have been invoked:

(a) Herbivory: It has been shown with $T$. repens (Dirzo and Harper, 1982), with L. corniculatus (Jones, 1962, 1966, 1972 and with both species (Crawford-Sidebotham, 1972) that slugs and/or snails prefer acyanogenic to 
cyanogenic plants when given the choice. Furthermore, the molluscs do not differentiate between the three types of acyanogenic $\left(\mathrm{G}_{-}\right.$, -E or --) plants.

(b) Temperature: Frost causes large ice cracks among the cells of leaves. When the leaves thaw the cyanoglucosides and the linamarase in a cyanogenic plant mix and $\mathrm{HCN}$ is released. There is some evidence of an association between the frequency of the cyanogenic form and temperature. A study by Daday (1954a) on samples of white clover collected all over Europe shows a clear relationship between the January mean temperature and frequencies of the dominant alleles at the two loci. The association is so pronounced that a $1^{\circ} \mathrm{F}\left(0.56^{\circ} \mathrm{C}\right)$ decrease in mean January temperature corresponds to a reduction of $4 \cdot 23$ per cent in the frequency of the $A c$ allele. Moreover, there is a strong correlation between the allele frequencies at the two loci. Other evidence shows a negative relationship between the frequencies of the $A c$ and $L i$ alleles and altitude (Daday, 1954b; De Arraujo, 1976). (In order to calculate the allele frequencies Daday (1954a, b; 1958) assumed the populations to be at Hardy-Weinberg equilibrium. No evidence was offered to justify this assumption).

Thus, there are two opposing selective forces acting on the genetic polymorphism. Neither, however, appears to distinguish between the G-, -E and -- plants. The models of theoretical population genetics show that these selective forces could, when acting together, maintain a genetic polymorphism at one locus, the other locus being monomorphic for the dominant allele, but are insufficient to explain either the polymorphism at both loci or the regularity of the cline in Europe corresponding to the January mean temperature. Thus the continued presence of the three acyanogenic phenotypes ( $\mathrm{G}-,-\mathrm{E}$ and --) in most populations must result from other factors or mechanisms having differential effect on these three phenotypes.

During studies on the distribution of cyanogenesis in $T$. repens in southern France it was found that different phenotypes can coexist simultaneously on the same plant. This report examines the incidence and heritability of this within-plant variation and discusses the role of natural selection in maintaining the genetic and phenotypic polymorphisms.

\section{MATERIALS AND METHODS}

Four sites at different altitudes in southern France, between Montpellier and the Cevennes, were chosen for study (table 1). At each site 50 stolons were collected. To minimize the possibility of sampling the same genet twice the distance between successive samples was at least $1 \mathrm{~m}$. The stolons were planted in individual cubical pots $(10 \times 10 \times 10 \mathrm{~cm})$ in the glasshouse and were allowed to root.

The compost used was a mixture of equal parts of humus (Sedagri), brown peat and soil from Camp Redon (Montpellier, clayey-silt) sterilised for 20 minutes. The glasshouse was heated in winter to keep the temperature above $15^{\circ} \mathrm{C}$ and cooled in summer to keep the temperature below $27^{\circ} \mathrm{C}$. No supplementary lighting was used.

The cyanogenic phenotype of the leaves was determined either by the modified Guignard picrate paper test (Corkill, 1940), or, using the same technique, by the Feigl and Anger (1966) reagent as adapted for plants by Tantisewie et al. (1969). All leaves tested were sampled at the same stage (folded leaves). Linamarase was isolated from the seeds of linseed (Linum usitatissimum L.) according to Coop (1940); linamarin was obtained commercially (Cal. Biochem.).

(a) All plants collected were first tested using the modified Guignard picrate test. Three or four additional tests were made at various time intervals using the Feigl and Anger reagent.

Table 1 The frequency of cyanogenic Trifolium repens at four sites located in southern France, between Montpellier and the Cevennes. The proportions are based on samples of 50 individuals per site

\begin{tabular}{llllcc}
\hline & & & \multicolumn{2}{c}{$\%$} & \\
Site & Altitude & Code & Location & Cyanogenic & Acyanogenic \\
\hline St Mathieu & $120 \mathrm{~m}$ & SM & plain & 77 & 23 \\
Ganges & $170 \mathrm{~m}$ & GA & valley & 80 & 20 \\
Le Coulet & $600 \mathrm{~m}$ & CO & top of slope & 15 & 85 \\
Col du Pas & $830 \mathrm{~m}$ & CP & top of slope & 4 & 96 \\
\hline
\end{tabular}


(b) Two plants from one of the sites were studied in further detail. A cutting was taken from each plant and established in the centre of a circular shallow pot of $50 \mathrm{~cm}$ radius. The growth of the stolons was mapped. When the plants were large enough, every terminal leaf of each stolon was collected and tested for cyanogenesis within the same $\frac{1}{2}$ hour period using the Feigl and Anger reagent. The position from which each leaf was taken was recorded on the map of the plant.

(c) Crosses were made on pairs of plants isolated in insect-proof cages. Pollination was done manually. The keel and the wing petals were removed using small forceps; this usually removes the stamens (but not invariably) and uncovers the stigma. The latter was brushed with the stamens of the male donor. Each flower was pollinated on every second day during the receptive period ( 5 to 6 days). Ten inflorescences per plant were pollinated. Flowers were not systematically emasculated because $T$. repens has an $S$-allele incompatibility system and is practically self-sterile (Davies, 1963). Each plant was used as both male and female parent and the seeds from the reciprocal crosses were harvested separately. Sixty seeds per cross were scarified by hand and left to germinate on filter paper in petri dishes. Successful germination ranged from between 25 and 55 seeds per cross. As soon as the radicle appeared, the seedlings were planted in individual pots. In order to evaluate heterogeneity ten leaves from each offspring were tested individually with the Feigl and Anger reagent for their cyanogenic phenotype within the same $\frac{1}{2}$ hour period. Only the plants that gave the same result for all 10 leaves are regarded as homogeneous; all the others show intra-individual heterogeneity.

\section{RESULTS}

Four or five repeated tests were made on individual plants in 1981 and 1982 and showed that different phenotypes can coexist simultaneously in the same plant. That is, some leaves on a plant could be cyanogenic whereas others, on the same plant, would contain only the cyanoglucosides, only the enzyme, or neither. Thus some plants are heterogeneous in the expression of their genotype for cyanogenesis, a phenomenon that has been called "intra-individual heterogeneity" (Till, 1983).

In heterogeneous plants, one type is usually more frequent than the others. There was a high proportion of heterogeneous plants at the two sites at high altitudes, $\mathrm{CO}$ and $\mathrm{CP}(600 \mathrm{~m}$ and $800 \mathrm{~m}$ ) where few plants were cyanogenic (table 1). Moreover, the intensity of the cyanogenic reaction was generally weak at these two sites. At the lowland sites, GA and SM, on the other hand the intensity of the reaction was stronger and the majority of plants were cyanogenic (table 1) and consistently so.

To evaluate the magnitude of these variations two plants were studied in detail in the spring of 1982. One of them was homogeneous GE and the other was heterogeneous, predominantly $-\mathrm{E}$. Both were chosen from the GA sample because these plants gave a strong reaction in the test. The homogeneous plant was tested twice and the heterogeneous one on 5 separate occasions. The results are shown in table 2 .

Even the homogeneous plant (GE) was not absolutely consistent ( 4 samples out of 141 were acyanogenic) when studied in this detail and the $\mathrm{HCN}$ released was greater by peripheral than by central leaves. In contrast, the heterogeneous plant showed great variation in the expression of both $G$ and $E$ (39 samples out of 274 ). Moreover, the

Table 2 Cyanotype of the terminal leaves of two plants at different dates. One plant was homogeneous, GE, the other was heterogeneous, predominantly -E. All the terminal leaves of the plants were collected and tested for their cyanogenic type within the same $\frac{1}{2}$ hour

\begin{tabular}{|c|c|c|c|c|c|c|}
\hline & \multirow[b]{2}{*}{ Date } & \multicolumn{4}{|c|}{ Number of leaves } & \multirow[b]{2}{*}{ Total } \\
\hline & & GE & $\mathrm{G}-$ & $-\mathrm{E}$ & -- & \\
\hline \multirow[t]{2}{*}{ Homogeneous } & 3 May 83 & 60 & 1 & 1 & 0 & 62 \\
\hline & 18 May 83 & 77 & 0 & 2 & 0 & 79 \\
\hline \multirow[t]{5}{*}{ Heterogeneous } & 2 May 83 & 10 & 3 & 27 & 3 & 43 \\
\hline & 19 May 83 & 6 & 1 & 58 & 0 & 65 \\
\hline & 9 June 83 & 2 & 0 & 50 & 0 & 52 \\
\hline & 23 June 83 & 2 & 0 & 58 & 0 & 60 \\
\hline & 22 July 83 & 4 & 0 & 42 & 8 & 54 \\
\hline
\end{tabular}


heterogeneity was greater for the glucosides than for the enzyme $(p<0 \cdot 05)$. Heterogeneity tended to decline somewhat during the experiment and so appears to be related to time or to another external factor. If the effects were caused by somatic mutation there should be a sectoring of the phenotypes within the plant. No such spatial structure was found.

Clearly we cannot distinguish absolutely between heterogeneous and homogeneous plants, but the detailed study does indicate that the initial groupings were sensible. Plants are more or less heterogeneous. For convenience, the less heterogeneous plants (where fewer than 10 per cent leaves are different from the predominant type) can still be called "homogeneous".

\section{Breeding studies}

In the summer of 1983, a series of four crosses was made to determine whether intra-individual heterogeneity was a heritable character. Two homogeneous plants (Ho1 and Ho2), both GE, and three heterogeneous plants ( $\mathrm{He} 1, \mathrm{He} 2$ and $\mathrm{He} 3$ ), all predominantly $\mathrm{G}$-, from the same population (GA) were used. The crosses and the results are described in table 3.

Most of the offspring from the cross between two homogeneous plants were homogeneous. Most of the offspring from the cross between two heterogeneous plants were heterogeneous. A majority of the offspring from the cross between heterogeneous and homogeneous plants were homogeneous. At first sight, therefore, homogeneity appears to be partly dominant.

The degree of heterogeneity was measured by the number of samples, out of ten tested per offspring, that differed from the predominant phenotype. The data in table 3 indicates that heterogeneity increases with the number of heterogeneous parents.

When we classify individual offspring on the basis of their predominant phenotype the simple model of Corkill (1942) can explain the results of some crosses ( $\mathrm{Ho} 1 \times \mathrm{He} 1$ and $\mathrm{He} 3 \times \mathrm{He} 2$ ) (table 4). The other two crosses, on the other hand, do not fit this model. In the $\mathrm{Ho} 1 \times \mathrm{Ho} 2$ cross, both plants must be heterozygous for both loci because all four phenotypes are found among the offspring. There is an excess of plants producing the enzyme compared with the number expected in Corkill's model $(p<0.05)$. Likewise, in the Hol $\times \mathrm{He} 2$ cross, too many plants produce the glucoside $(p<0.05)$. More elaborate models involving more major genes can be developed to explain these progenies. The simplest hypothesis involves at least two major loci for each function, but there is no independent evidence to support this.

\section{DISCUSSION}

The polymorphism of cyanogenesis in $T$. repens is of interest to plant breeders because the best agronomic types are the highest in HCN content (Ware, 1925; Doak, 1933). The system is also of great interest to population geneticists. Not only is it one of the few apparently clear-cut genetic polymorphism in plants, but also some of the selective forces that maintain the polymorphism have been identified, although the system is not fully understood. Most of the formal breeding work suggests a system of two independent loci, one for the cyano-glucosides and the other for linamarase giving $F_{2}$ ratios of $9: 7$ for cyanogenic to acyanogenic types and $9: 3: 3: 1$ for $\mathrm{GE}, \mathrm{G}-$, $-\mathrm{E}$ and --. Some aberrant progenies have been recorded, (Williams, 1939; Corkill, 1942; Chakravarty,

Table 3 Distribution of the offspring of crosses between homogeneous (Ho) and heterogeneous $(\mathrm{He})$ plants according to their heterogeneity

\begin{tabular}{|c|c|c|c|c|c|}
\hline \multirow[b]{3}{*}{ Parents } & \multicolumn{5}{|c|}{ Number of offspring } \\
\hline & & & & ogeneo & \\
\hline & Homogeneous & 1 & 2 & $3-5^{*}$ & Total \\
\hline $\mathrm{Ho} 1 \times \mathrm{Ho}_{2}$ & 43 & 7 & 0 & 1 & 8 \\
\hline $\mathrm{Ho} 1 \times \mathrm{He} 2$ & 39 & 7 & 1 & 0 & 8 \\
\hline $\mathrm{Hol} \times \mathrm{Hel}$ & 29 & 6 & 5 & 5 & 16 \\
\hline $\mathrm{He} 3 \times \mathrm{He} 2$ & 17 & 11 & 7 & 7 & 25 \\
\hline
\end{tabular}

* The numbers indicate the number of samples, out of 10 , per plant, that gave a different result than the predominant cyanotype.

All crosses were made with $\mathrm{Ho}$ and He both as maternal and paternal parents. As no differences were found between the progeny from the reciprocal crosses the data have been combined. 
Table 4 Observed (o) and expected (e) values for each function ( $G$ or $E$ ) for four crosses between homogeneous ( $\mathrm{Ho}$ ) and heterogeneous ( $\mathrm{He})$ plants. The expected values are calculated according to the two loci two alleles model. The hypothetical genotype of the parents is noted for each cross

\begin{tabular}{|c|c|c|c|c|c|c|c|}
\hline & & & & & Off & & \\
\hline & ren & & & G & - & $E$ & - \\
\hline Hol (GE) & $x$ & Ho2 (GE) & 0 & 33 & 18 & 47 & $4^{*}$ \\
\hline AcacLili & & AcacLili & $\mathrm{e}$ & $38 \cdot 25$ & $12 \cdot 75$ & $38 \cdot 25$ & $12 \cdot 75$ \\
\hline Hol (GE) & $x$ & Hel (G-) & 0 & 35 & 10 & 26 & 19 \\
\hline AcacLili & & Acaclili & $\mathrm{e}$ & 33.75 & $11 \cdot 25$ & $22 \cdot 50$ & $22 \cdot 50$ \\
\hline Hol (GE) & $x$ & $\mathrm{He} 2\left(\mathrm{G}_{-}\right)$ & 0 & 44 & $3^{*}$ & 27 & 20 \\
\hline AcacLili & & Acaclili & $\mathrm{e}$ & $35 \cdot 25$ & $11 \cdot 75$ & $23 \cdot 50$ & $23 \cdot 50$ \\
\hline $\mathrm{He} 3\left(\mathrm{G}_{-}\right)$ & $x$ & $\mathrm{He} 2(\mathrm{G}-)$ & 0 & 42 & 0 & 0 & 42 \\
\hline AcAclili & & Acaclili & $\mathrm{e}$ & 42 & 0 & 0 & 42 \\
\hline
\end{tabular}

${ }^{*} p<0 \cdot 05$.

1963), but these have either been overlooked or attributed to modifier genes segregating in these particular families (Atwood and Sullivan, 1943). Aberrant progenies have also been recorded in formal breeding studies with $L$. corniculatus (Ramnani and Jones, 1984) even though an independent genetic marker (colour of the keel petals) segregated normally in these same progenies.

In my experiment, two crosses out of four gave aberrant ratios and suggested multigenic inheritance. Moreover, by testing different leaves of the same age from the same plant at the same time, I have found that a plant can show simultaneously two or more possible phenotypes for cyanogenesis, a phenomenon termed intra-individual heterogeneity (Till, 1983).

In the literature on cyanogenesis the stability of the phenotype is usually not contested (except for Ellis et al., 1977; Ramnani and Jones, 1984 with L. corniculatus), and is even sometimes asserted. Ware (1925), for example, wrote "not only was the property of cyanogenesis constant from one year to another, but so also, to a marked degree, was the intensity of the colour change". (He was using the sodium picrate test on T. repens.) In contrast, Rogers and Frykolm (1937) found individual plants of $T$. repens that could give both negative and positive reactions when tested for their ability to release HCN. Williams (1939) also observed that "duplicate tests sometimes gave conflicting results". De Waal (1942) observed diurnal variation within plants. Generally, no within-plant variation is mentioned when the authors have worked with plants grown from commercially available seeds (e.g., Corkill, 1940, 1942; Maher and Hughes, 1973). The authors who worked with wild plants (Rogers and Frykolm, 1937; Atwood and Sullivan, 1943) found some variation. This probably means that intra-individual heterogeneity has been eliminated by human selection. When intra-individual heterogeneity has been observed the successive samples have usually been taken at different times of the year. Heterogeneity was therefore observed in time, but not in space and attributed to flexibility in the expression of the genotype related to temperature or season (e.g., with L. corniculatus, Ellis et al. 1977).

Only rarely have repeated samples been taken from the same individuals. More usually people have tested only one sample of leaves from each individual plant and could not, therefore, have detected intra-individual heterogeneity. However, this intra-individual heterogeneity of phenotype means that the presence of different cyanogenic phenotypes in a population may neither correspond with nor result from genetic diversity at the $A c$ and $L i$ loci. At the extreme, intra-individual heterogeneity could account for what appears to be a polymorphism at both loci even though all individuals in the population could be genotypically $A c L i$. We now have two interrelated problems. The breeding evidence shows that there is a genuine genetic polymorphism for cyanogenesis in $T$. repens, while at the same time the genetic polymorphism is being mimicked by a phenotypic polymorphism. Are the same selective factors involved in the two situations?

The intra-individual heterogeneity means that the frequency of cyanogenesis in natural populations does not really refer to populations of plants, but rather to populations of leaves. We have, therefore, populations of leaves of $T$. repens in which the frequency of the cyanogenic form is positively correlated with the January isotherms in Europe (Daday 1954a), or negatively with altitude (Daday, 1954b; De Arraujo 1976). The plants used 
in those experiments were obtained as seeds or cuttings from natural habitats. They were grown up and tested in a glasshouse and therefore all plants were in essentially the same environment when tested. Thus what was observed was not a measure of the frequency of the cyanogenic phenotypes in situ, but probably a more direct effect of the underlying genotype of the plants.

The intra-individual heterogeneity is less marked in plants that would be scored as GE than in the other three phenotypes (Till, 1983). These GE plants are relatively stable irrespective of altitude although they are less strongly cyanogenic at higher altitudes. Furthermore GE plants are less common at higher altitudes. This suggests that there is a positive response by the plant to selection against the GE phenotype in addition to the totally passive one of GE plants being eliminated by selection. At some locations, selection appears to have favoured plants that are capable of changing phenotype in response to some environmental cue. This situation is similar to the one described by Jones and Ramnani (1985) in L. corniculatus, but whereas they were discussing changes of phenotype with time the situation in individuals of $T$. repens concerns differences of phenotype in space. The outcome may well be the same in that the frequency of cyanogenic plants/leaves in a population can change without the elimination of any individuals (see Jones and Ramnani, 1985). This type of "phenotypic plasticity" is very flexible and economical because the substances involved can be recovered, whereas morphological changes are fixed.

Intra-individual heterogeneity can be observed at two levels. Two leaves from the same plant and even leaflets from the same leaf can have different phenotypes (Till, 1983). This kind of heterogeneity has also been found at the cell level (Kakes, 1985) and has been associated with the cyanoglucosides and linamarase being stored separately. Whether there is a real difference between these two situations remains to be seen.

The inheritance of both intra-individual heterogeneity and the main phenotypes seem to involve several major and minor genes. Temperature, among other factors appears to be a selective agent acting on the phenotypes produced by alleles of these genes and thus gives rise to the distributions observed by Daday (1954a) and others.

As Maynard-Smith (1982) has pointed out, some behaviour that cannot be understood in terms of deterministic models may be explained by the theory of games. One of the alternative models proposed is a totally randomised one where the strategy of the organism is unpredictable. In the case I have described, individual white clover plants do not seem to have a deterministic strategy as no pattern of variation can be detected in time or in space. It appears that for each plant the cyanotype of a leaf is determined at random. Consequently, where there are differences between leaves within the same plant and between plants there is a cyanogenesis mosaic in the field that is highly diversified both in space and in time. This strategy is not favourable to herbivores as they cannot predict the cyanotype of a leaf from the previous one eaten or sampled.

$T$. repens is a species with very great genetic variability and plasticity for growth and flowering characters (Burdon, 1980). Turkington et al. (1979) have demonstrated variation in agressiveness towards a standard clone and found a great diversity of types at the local scale in the field. The plant also shows great diversity in the pattern of markings on the leaves (Carnaham et al., 1955; Cahn and Harper, 1976). Intra-individual cyanogenic heterogeneity is another element showing the extreme intra-specific diversity both between and within individuals of $T$. repens $L$.

Acknowledgements This work was part of a collaborative programme on the "Polymorphism in white clover" and supported by grants from: Centre National de la Recherche Scientifique (ATP Internationale 1981), Scientific Research Council (France-UK Collaborative Study, RDL 54), and NATO (Research Grant 032-81). I wish to thank Professor G. Valdeyron, Drs P. H. Gouyon and P. Jacquard for their help and advice throughout this work. Assistance in experimental work was provided by $M$. Beltran and the staff of the CEPE: experimental station. 1 am grateful to Professors J. L. Harper and D. A. Jones for stimulating discussions. Professor Jones kindly read and criticised the manuscript in preparation.

\section{REFERENCES}

ARRAUJO. A 1)I: 1976. The relationship between altitude and cyanogenesis in white clover (Trifolium repens L.). Heredity, 37, 291-293.

ATW()()I, S. S. AND SUIIIVAN, I. I, 1943. Inheritance of a cyanogenetic glucoside and its hydrolysing enzyme in Trifolium repens L. Journal of Heredity, 34, 311-320.

BANSAI, R. D, 1971. Inheritance of cyanogenctic enzymes in Lotus corniculatus L. Indian Journal of Agricultural Science, 41, 67-69.

B()IRSMA, P'., KAKES, P. ANI) S(IIRAM, A.W. 1983. Linamarase and $B$-glucosidase activity in natural populations of Trifolium repens. Acta Botanica Neerlandica, 32, 39-47.

BU RIDON, J, J. 1980. Intra-specific diversity in a natural population of Trifolium repens L. Journal of Ecology, 68, 717-735.

CAHN, M. (i. AND HARPER, I. 1.. 1976. The biology of the leaf mark polymorphism in Trifolium repens L. I. Distribution of phenotypes at a local scale. Heredity, 37, 309-325. 
CARNAHAN, H. L., HILL, H. D., HANSON, A. A. AND BROWN, K. G. 1955. Inheritance and frequencies of leaf markings in white clover. Journal of Heredity, 46, 109-114.

CHAKRAVARTY, A. K. 1963. Inheritance of cyanogenesis in white clover. Indian Journal of Genetics and Plant Breeding, 23, 185-196.

COllinge, D. B. AND Hughes, M. A. 1984. Evidence that linamarin and lotaustralin, the two cyanogenic glucosides of Trifolium repens L., are synthesized by a single set of microsomal enzymes controlled by the Ac/ac locus. Plant Science Letters, 34, 119-125.

COOP, I. E. 1940. Cyanogenesis in white clover (Trifolium repens L.) III. A study of linamarase, the enzyme which hydrolyses lotaustralin. New Zealand Journal of Science and Technology $B, 22,71-83$.

CORKILL, L. 1940. Cyanogenesis in white clover (Trifolium repens L.) 1. Cyanogenesis in single plants. New Zealand Journal of Science and Technology B, 22, 65-67.

CORKILL, L. 1942. Cyanogenesis in white clover (Trifolium repens $\mathrm{L}$.) V. The inheritance of cyanogenesis. New Zealand Journal of Science and Technology B, 23, 178-193.

CRAWFORID-SIDEBOTHAM, T. J. 1972. The role of slugs and snails in the maintenance of the cyanogenesis polymorphism of Lotus corniculatus L. and Trifolium repens L., Heredity, 28, 405-411.

CUTLER, A. J. AND CONN, E. E. 1982. The synthesis, storage and degradation of plant natural products: cyanogenic glucosides as an example. Recent Advances in Phytochemistry, 16, 249-271.

DADAY, H. 1954a. Gene frequencies in wild populations of Trifolium repens L. 1. Distribution by latitude. Heredity, 8 , $61-78$.

DADAY, H. 1954b. Gene frequencies in wild populations of Trifolium repens, L. I1. Distribution by altitude. Heredity, $8,377-384$.

DADAY, H. 1958. Gene frequencies in wild populations of Trifolium repens L. III. World distribution. Heredity, 12, 169-184.

DAVIES, W. E. 1963. Leaf markings in Trifolium repens. In Darlington, C. D. and Bradshaw, A. D. (eds.) Teaching Genetics, Oliver and Boyd, Edinburgh and London, pp. 94-98.

DAWSON, C. D. R. 1941. Tetrasomic inheritance in Lotus corniculatus L. Journal of Genetics, 42, 49-72.

DIRZO, R. AND HARPER, J. L. 1982. Experimental studies on slug-plant interactions. 111. Differences in the acceptability of individual plants of Trifolium repens $L$. to slugs and snails. Journal of Ecology, 70, 101-117.

DOAK, B. W. 1933. A chemical method for the determination of type in white clover. New Zealand Journal of Science and Technology, 14, 359-365.

ELLIS, W. M., KEYMER, R. J. AND JONES, D. A. 1977. The effect of temperature on the polymorphism of cyanogenesis in Lotus corniculatus L. Heredity, 38, 339-347.

FEIGL, F. AND ANGER, V. 1966. Replacement of benzidine by copper ethylacetoacetate and tetra-base as spot-test for reagent for hydrogen cyanide and cyanogen. Analyst, 91, $282-284$.
HUGHES, M. A. AND STIRLING, J. D. 1982. A study of dominance at the locus controlling cyanoglucoside production in Trifolium repens L. Euphytica, 31, 477-483.

JONES, D. A. 1962. Selective eating of the acyanogenic form of the plant Lotus corniculatus L. by various animals. Nature, 193, 1109-1110.

JONES, D. A. 1966. On the polymorphism of cyanogenesis in Lotus corniculatus L. I. Selection by animals. Canadian Journal of Genetics and Cytology, 8, 556-567.

JONES, D. A. 1972. Cyanogenic glucosides and their function. In Harborne, J. B. (ed.) Phytochemical Ecology, Academic Press, London, pp. 103-124.

JONES, D. A. AND RAMNANI, A. D. 1985. Altruism and movement of plants. Evolutionary theory, 7, 143-148.

KAKES, P. 1985. Linamarase and other $B$-glucosidases are present in the cell walls of Trifolium repens leaves. Planta, $166,156-160$.

KOJIMA, M., POULTON, J. E., THAYER, S. S. AND CONN, E. E. 1979. Tissue distribution of Dhurrin and of enzymes in its metabolism in leaves of Sorghum bicolor. Plant Physiology, $63,1022-1028$.

MAHER, E. P. AND HUGHES, M. A. 1973. Studies on the nature of the $\mathrm{Li}$ locus in Trifolium repens $\mathrm{L}$. II. The effect of genotype on enzyme activity and properties. Biochemical Genetics, 8, 13-26.

MAYNARD-SMITH, J. 1982. Evolution and the theory of games, Cambridge University Press, Cambridge, $224 \mathrm{pp}$.

RAMNANI, A. D. AND JONES, D. A. 1984. Genetics of cyanogenesis, cyanoglucoside and linamarase production in the leaves of Lotus corniculatus L. Pakistan Journal of Botany, 16, 145-154.

ROGERS, C. F. AND FRYKOLM, O. C. 1937. Observations on the variations in cyanogenetic power of white clover plants. Journal of Agricultural Research, 55, 533-537.

TANTISEWIE, B., RUIJGROK, H. W. L. AND HEGNAUER, R. 1969. Die verbreitung der Blausaure bei den Cormophyten. 5. Mitteilung: uber Cyanogene verbindungen bei den Parietales und bei einigen weiteren Sippen. Pharmaceutisch Weekblad, 43, 1341-1355.

TILL. 1. 1983. Etude de la variabilite de la cyanogenese chez le trefle blanc (Trifolium repens $L$.) dans la region de Montpellier. These de Docteur Ingénieur. Institut National Agronomique, Paris-Grignon. France.

TURKINGTON, R., CAHN, M. A., VARDY, A. AND HARPER, J. L 1979. The growth, distribution and neighbour relationships of Trifolium repens $\mathrm{L}$. in a permanent pasture. 111. The establishment and growth of Trifolium repens $\mathrm{L}$. in natural and perturbed sites. Journal of Ecology, 67, 231-243.

WAAL, D. DE 1942. Het cyanophore karacter van witte klaver, (Trifolium repens L.). Thesis Landbouwhoogeschool, Wageningen, The Netheriands.

WARE, W. M. 1925. Experiments and observations on forms and strains of Trifolium repens L. Journal of Agricultural Science, $15,47-67$.

WILLIAMS, R. D. 1939. Genetics of cyanogenesis in white clover (Trifolium repens). Journal of Genetics, 38, 357-365. 